\title{
Summer scholarship project: Designing and building a multi-purpose micro-farm structure as a pedagogical strategy for Architectural Engineering Technology students
}

\section{Mr. Eugene Kwak, Farmingdale State College, State University of New York}

Eugene Kwak is a licensed architect and an assistant professor in the Department of Architecture and Construction Management at Farmingdale State College, State University of New York. He has been running research and grant-based projects, including the George Washington Carver Community garden design in New Iberia, Louisiana. During his tenure in the private sector, he focused on technology-based green and sustainable work including the New Housing New York Legacy Project. Eugene's entry for the Intersection: Grand Concourse 100 and Reinventing Grand Army Plaza Competition was selected as one of the top 30 proposals to be included in a public exhibition. As a student at Columbia University, Eugene earned the Lucille Smyser Lowenfish Memorial Prize, which is given to the graduating student whose work is most outstanding. He has taught architectural design, urban design seminars, and various workshops at Parsons The New School, Pratt Institute, and New York Institute of Technology. Eugene received a Bachelor of Architecture from Carnegie Mellon University and a Master of Science Degree in Architecture and Urban Design from Columbia University. 


\title{
Summer scholarship project: Designing and building a multi- purpose micro-farm structure as a pedagogical strategy for Architectural Engineering Technology students
}

\begin{abstract}
Constructing a full-scale mock-up is commonly used in the architectural industry, and it is invaluable to the design outcome. It provides feedback on the appearance, scale, material, and constructability. This process can also be adopted as a teaching strategy in a classroom, especially when considering that a hands-on learning experience increases student engagement and information retention. This work-in-progress paper describes a summer scholarship project, led by the author and students from the Architectural Engineering Technology program who designed and built a micro-farm structure that doubles as outdoor furniture. The primary purpose of this project is to evaluate the feasibility of micro-farm structures as a new pedagogical strategy in architectural courses, and to simulate a multi-disciplinary course that employs experiential learning. This will set a precedent as a scalable model for other institutions to replicate and to share the lessons learned from the process.
\end{abstract}

\section{Introduction}

Based on the previous study [1], the goal of this research is to develop a pedagogical strategy in the Department of Architecture and Construction Management at Farmingdale State College, State University of New York that proposes to design and build a multi-functional urban microfarm structure as a teaching tool. This multi-disciplinary project aspires to integrate a hands-on learning experience for the students to apply knowledge obtained from other courses and evolve the discourse around architectural, social, and environmental issues. To initiate this research, the project required funding for the construction material, a location for the design site, and student volunteers. The author sought sources of funding within the affiliated institution and identified the annual Summer Scholarship Support as a potential source. The application requirement with the objectives and outcomes aligned with the intention of this study. Subsequently, the scholarship has been awarded to provide funding for the construction material. The planning of this project also involved coordination with the regional food bank, Island Harvest, who is currently operating a community garden on a leased plot on campus. The garden provided sufficient context for the participating students to generate a wide range of design schemes. Also, faculty from the Department of Urban Horticulture \& Design collaborated during the planning phase. Two of the Architectural Engineering Technology students from the author's previous courses, Konstantinos Neofitos and Daniella Lima De Freitas Smyth, volunteered to participate in this research.

\section{Process}

\section{Pedagogical Approach}

The pedagogical strategy for this pilot project aligns with Inductive Teaching and Learning Methods, particularly Project-based learning (PBL). An alternative to a traditional deductive 
method, PBL motivates students to discover new knowledge when they are given a complex real-world problem to solve [2]. The students are confronted with challenges that require the application of previously obtained knowledge. Also, this pilot project has a broad scope that demands open-ended research processes, problem-solving discovery, communication, teamwork skills, and knowledge in the issues of professional practice. The instructor's role in this project is to define design parameters by establishing expectations of the design skill development, conceptual and technical understanding. Also, a bi-weekly reporting structure was established with the students to share their research progress and design issues. Students were asked to create more frequent interim sessions to communicate their common challenges and find solutions themselves instead of receiving guidance from the instructor. This self-guided process allows students to acquire deeper knowledge by analyzing, evaluating, and creating, which promotes higher-order thinking in Bloom's Taxonomy [3].

\section{Site analysis}

The participating students began their research in June 2019 with the site analysis, which included surveying and documenting the existing site, as shown in figures 1.1 and 1.2. This analysis is a critical step to provide a dimensional, informational, and conceptual reference for the design process, and it serves as a source of inspiration. The gathered information included the images and measurements of the site, which were regenerated as an underlayment for their initial design sketches. Also, during this investigation, they directly interacted with the regional food bank to incorporate community outreach as part of their design strategy. The students worked closely with the organization's coordinator, who provided the perspective of the client, demanding the functional needs of the end-user. During the preliminary design phase, the students were constantly reminded of the pragmatic requirements which balanced creative solutions and the practical application. For example, the field was under tremendous weed pressure, and management became the highest priority for the organization. It was critical to propose an integral design that can suppress weed and reduce maintenance demand. This was the first time the students encountered an authentic problem, which is a key component of PBL [4]. In this problem-solving process, faculty from the Department of Urban Horticulture \& Design played a role as the consultants who provided input on a crop plan and planting schedule. This session helped the students to determine the location of vegetation, form, and orientation of the structure based on the solar exposure, sun path, circulation, and accessibility of the user. The interaction with multiple parties provided students a broader perspective on the architect-client, architect-consultant relationship, and the value of the interactive and iterative design process.

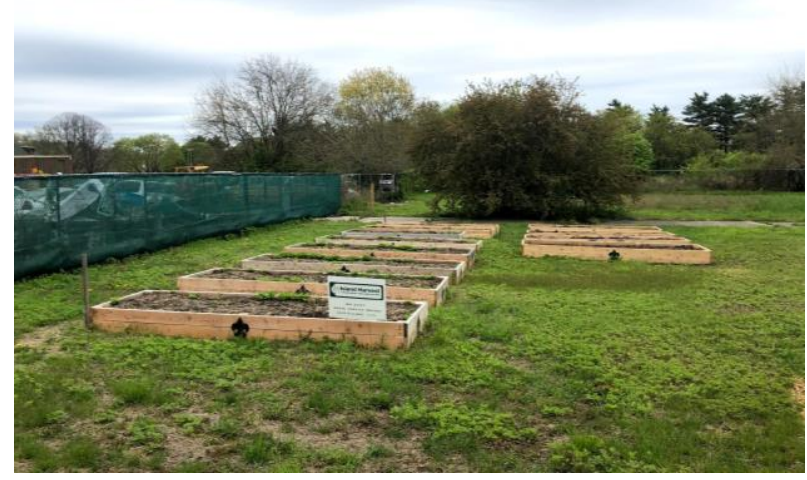

Figure 1.1 Community Garden at the campus

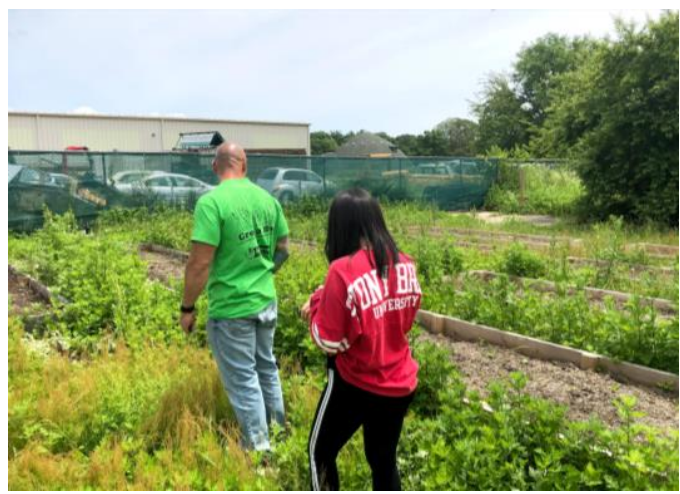

Figure 1.2 Site analysis 
Site visit

Simultaneously with their site analysis, the students conducted precedent studies to find examples with a similar scale, material, design strategy, program, and sustainability goals. Due to the unique nature of this multi-disciplinary project, which includes horticultural design and outdoor furniture design, the investigation led to an academic example, street furniture designed by Parsons School of Design in New York City, as seen in figure 1.3. Street Seats is a collaboration project between the Parsons School of Design and the New York City Department of Transportation (DOT) [5]. This is a part of an elective course in the School of Constructed Environments, Design Build where the project is designed and constructed by students. Over the course of fifteen weeks, students generate individual designs, combine into group schemes, arrive at a single design, and construct the structure. Street Seats considers user experience, context, sustainability, and material selections. This installation reclaims two parking spaces on the corner of $13^{\text {th }}$ street and Fifth Avenue in front of the school.

A field trip was organized to visit Street Seats on the corner of $13^{\text {th }}$ street and Fifth Avenue in New York City. The visit was a significant inspiration for the students to generate a diverse design idea. Students discovered the benefits of using modular lumber as they saw the correlations between the overall dimension and the individual lumber. Also, they studied how size and proportion correspond to the function of space. They inspected the corner joinery detail and noted the types of fasteners and the cuts made for the angular joints, as shown in figure 1.4. This observation provided a chance to see the real-world application of the details, components, assembly, and fabrication of a full-scale structure first-hand.

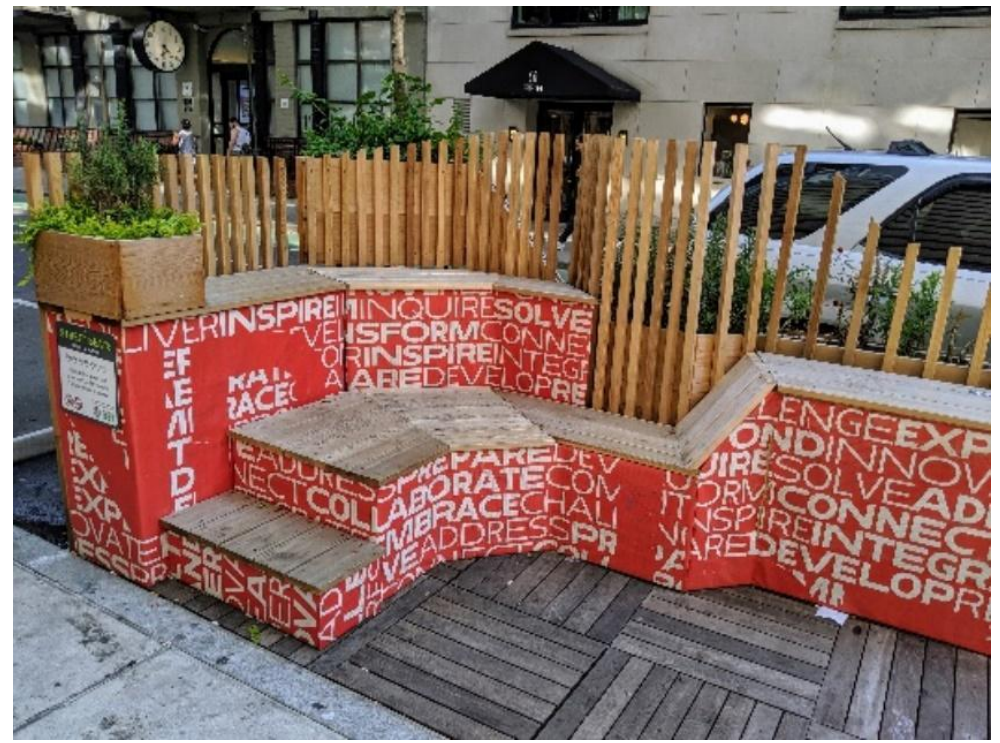

Figure 1.3 Parsons School of Design, temporary street furniture on the corner of 13th St. and Fifth Avenue, New York City

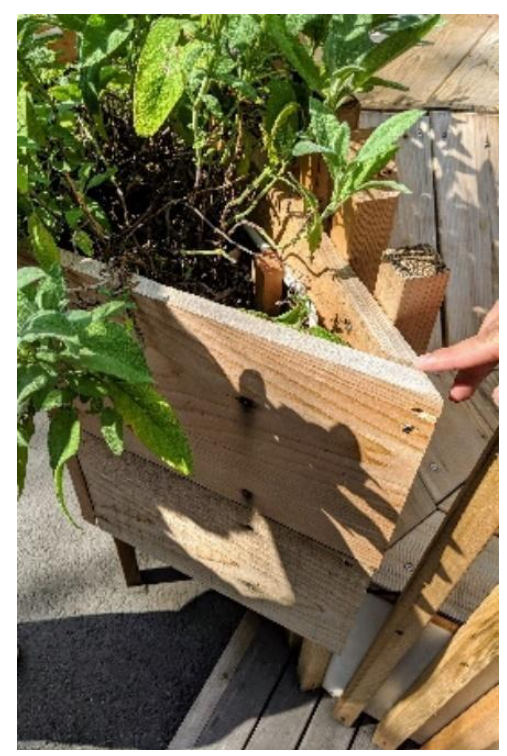

Figure 1.4 Corner detail of the structure

Another field trip took place at the High Line [6] in New York City, as seen in figures 1.5 \& 1.6. The High Line park showcases a successful design strategy that integrated multi-faceted concepts and programs. The students were interested to learn the landscape strategy, mainly the composition of vegetation and the hardscape. In addition, they analyzed the exterior furniture design, which is an essential component at the High Line for providing social activities for the 
visitors. The furniture analysis included the design, material, assembly, ergonomics, accessibility, and user behavior. The High Line catalyzed development in the surrounding neighborhood and made numerous social and economic impacts. This visit resonated with the students and their mission to revitalize the community garden as a place of gathering for the local community.
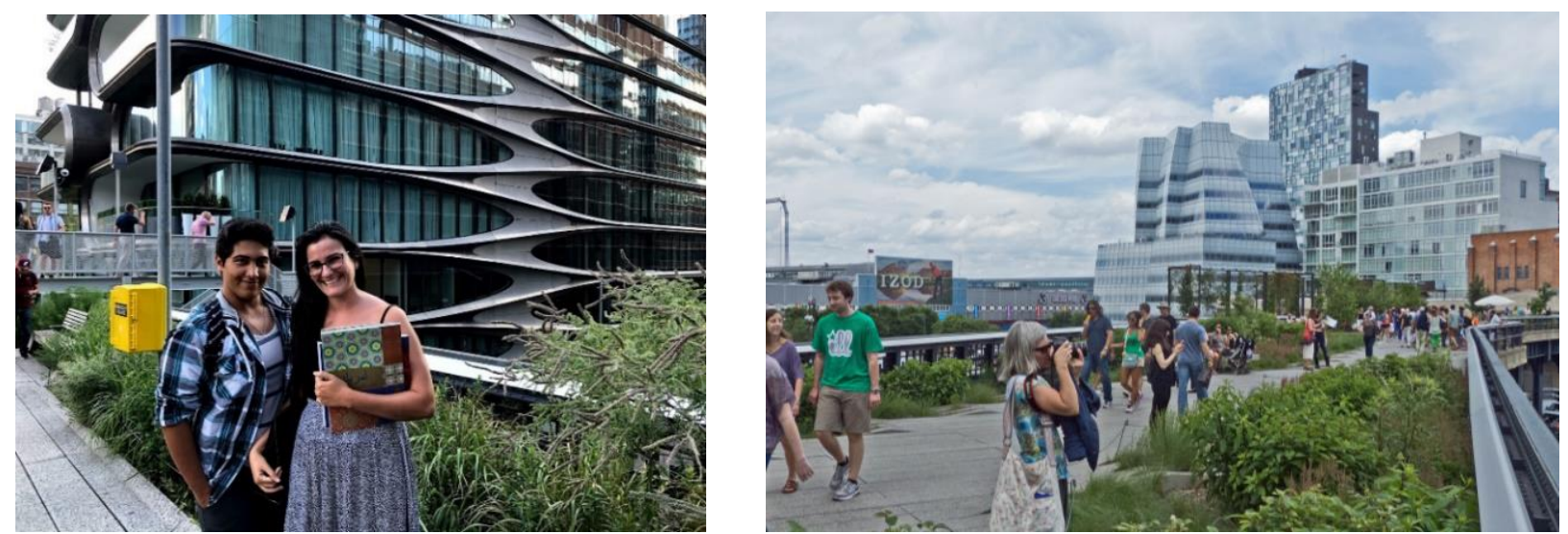

Figure 1.5 \& 1.6 Participating students, Konstantinos Neofitos and Daniella Lima De Freitas Smyth, visiting the High Line, NYC

A traditional classroom setting limits student learning and engagement. Therefore, many technical courses initiated Experiential Learning [7] to enhance the real-world experience for the students. The courses integrated active learning strategies with diverse hands-on learning activities and various demonstrations to increase student participation. Contrary to this effort, the design courses have not emphasized the importance of site visit, which offers design inspiration, application of theories, and discovery of new problem-solving approaches. The site visit during the summer scholarship project provided the students with a chance to see the creative design process and implementation.

Design process

After the field trip to New York City, students generated multiple conceptual sketches. In this phase, they were able to externalize their ideas in visual form and evaluate the method of ideation, conceptualization, choice of medium, mode of representation, and the overall design scheme. The initial 2-dimensional sketches conveyed the conceptual idea of interacting primitive geometries and their relationship. The basic design strategy included a subtractive and additive transformation of basic forms. The subtraction of the forms allowed the creation of circulation and communal space, as exhibited in figure 2.1. The pathways also provide access to the raised beds from all angles. A lead pencil was used during the sketching process, which provided artistic representation, and this level of crudeness provided room for creative interpretation, as shown in figure 2.2. Students generated multiple options, and the instructor responded with design feedback for refinement. A few selected options were translated into a more precise AutoCAD drawing, which provided an accurate assessment of the design schemes and allowed the students to make an update with more precise dimensions. This AutoCAD drawing became a basis for extrusion of 3-dimensional massing, as exhibited in figure 2.3. Then the massing is incorporated with the wood texture and vegetation in the post-production phase, as shown in figure 2.4. This representation offered students an opportunity to evaluate the final 
design. Throughout the drafting, modeling, and visualization process, the design continued to improve, as students were able to visualize the spatial relationship, proportion, and scale of the structure.

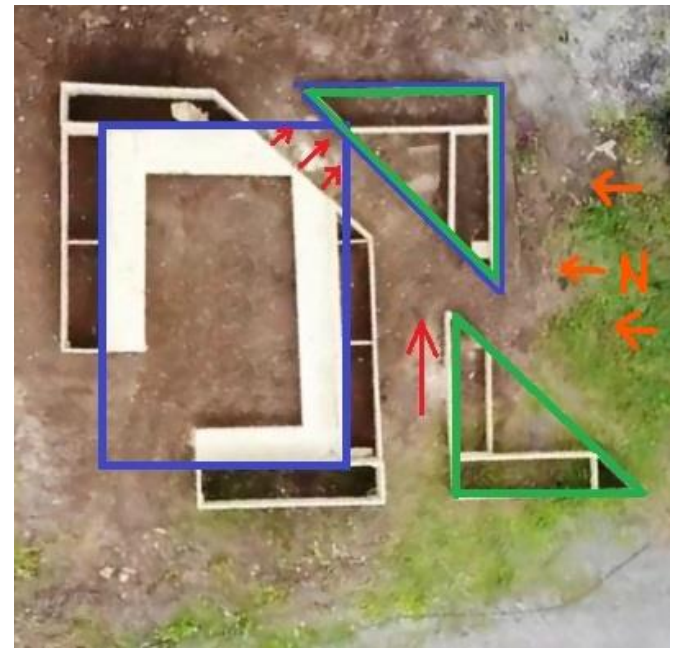

Figure 2.1 Geometric abstraction and interaction

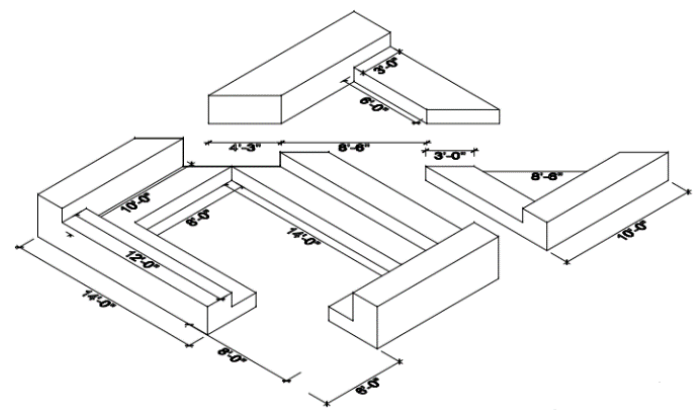

Figure 2.3 3d massing model

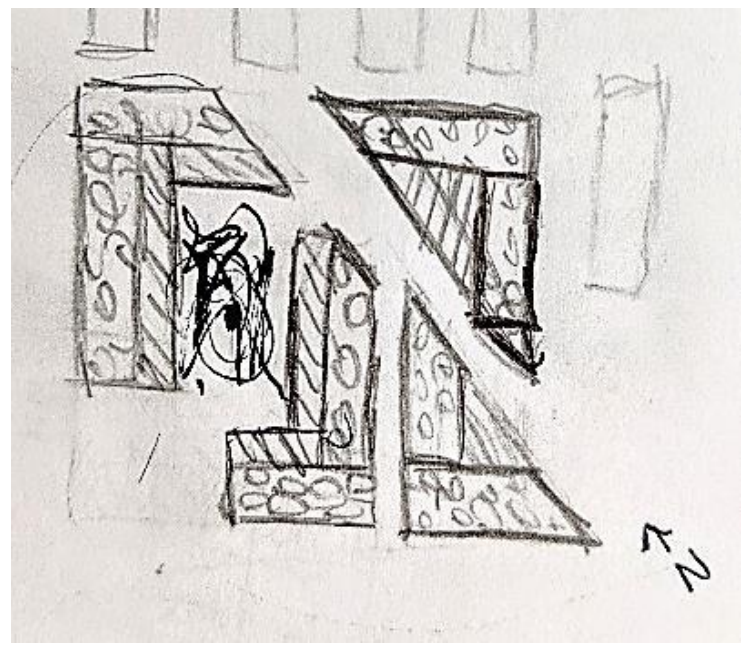

Figure 2.2 Conceptual 2d sketch

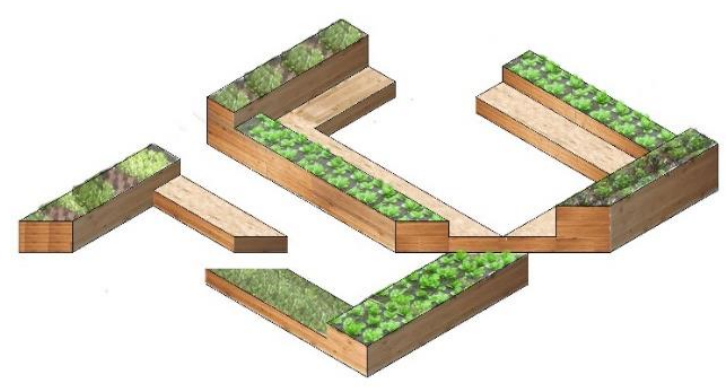

Figure 2.4 Rendered image of the raised beds

\section{Design and material}

The finalized 22' $\times 30$ ' urban micro-farm structure integrated multiple raised beds that doubled as outdoor furniture. This student design is a culmination of the site analysis, site visit, precedent, and morphological studies. This design also incorporated prior design knowledge from Architectural Design course that emphasized form, space, and order. During the design phase, the students researched the material options, and they selected cedar as their primary material. The main benefit of using cedar is that its natural oil provides rot resistance and insect repellence. After the design was finalized, the students prepared material take-off based on the size of the structure and the construction methods. The material take-off is an estimated list of supplies with the respective quantity, as listed in table 1.1.

\begin{tabular}{|l|l|}
\hline Quantity & Description \\
\hline 48 & $2 \times 12-12$ dimensional lumber \\
\hline 3 & $2 \times 6-12$ dimensional lumber \\
\hline
\end{tabular}

Table 1.1 Material take off for lumber 


\section{Challenges}

During the design and implementation process, the research team faced four major challenges: the lumber price, project site, Institutional Review Board (IRB) process, and coordination during the construction phase.

Using the material take-off, the students received pricing from various lumber yards and discovered the cedar would exceed the budgetary limit. After a careful review of the design and material option, the team determined that cedar will no longer work, and the project needs more cost-effective material. The students also explored alternative design options that substantially reduce the size and material needs. The decision was to switch the material from cedar to pressure treated-wood, as shown in figure 3.1. This challenge during the material selection was a critical shortcoming for this project due to the agricultural aspect with the edible production. Students investigated the effects of pressure-treated wood on edible plants and found ways to prevent contamination with an interior liner that separates wood and soil. The design scheme has evolved into mainly an outdoor garden and partial edible production. The list of plant types is shown in table 2.1 .

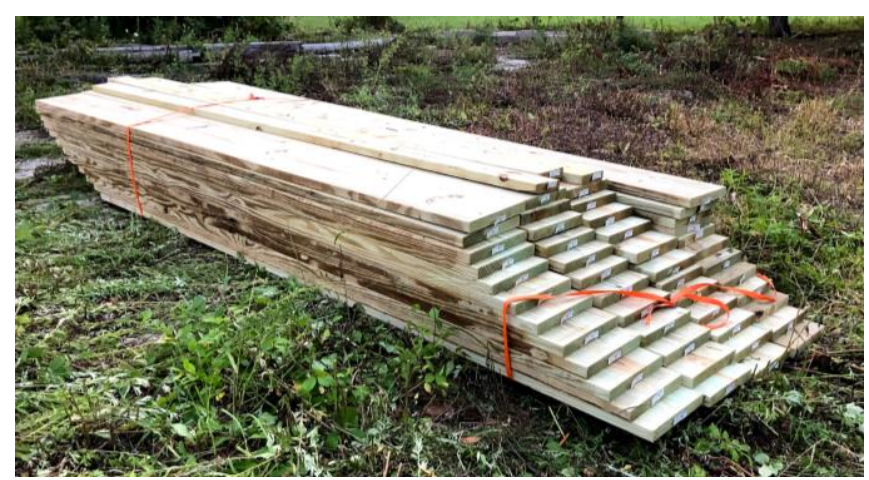

Figure 3.1 pressure-treated wood

\begin{tabular}{|c|l|}
\hline Quantity & Description \\
\hline 5 & Purple Mist Flower \\
\hline 5 & Little Blue Stem \\
\hline 5 & Coreopsis \\
\hline 10 & Snakeroot \\
\hline 10 & Butterfly Weed \\
\hline 5 & Blazing Star \\
\hline 5 & Bee Balm \\
\hline 5 & Rudbeckia Hirta \\
\hline 5 & Aster \\
\hline
\end{tabular}

Table 2.1 Plant list

Another challenge was the site access. The project site is managed by the regional food bank, Island Harvest and the facilities management at Farmingdale State College. During the planning phase, an initial agreement was made with the regional food bank regarding the site access. Although the site is solely managed by the organization, any new structure on campus needs to be reviewed and approved by the facilities management. The author underestimated the complexity of the property management structure and the rigorous review process associated with the process. This delay affected the construction schedule, and the project needed to be built elsewhere with site access.

Before the construction, the author applied to the Institutional Review Board (IRB), which facilitates the ethical conduct of research and oversees research involving human subjects. The IRB commented that the involvement of students with construction tools and the risk associated with such activities during the construction process would jeopardize the safety of the students. The board required Form-A which has much more rigorous, lengthy, and stringent provisions that would delay the project beyond the planned timeframe. To avoid this delay, the author proposed a Role-playing Active Learning strategy [7]. Students would "act-out" as architects to 
provide design information and avoid any risks involved in the construction process. They would work closely with the author, who played the role of a contractor during the construction process. This alteration shifted the dynamic of the study from students' direct involvement in the full-scale building process to a role-playing activity. The benefit of the new Active Learning strategy is that it simulates a professional relationship between the architect and contractor.

The fabrication for the construction required precise measurements and information from the design team. The working drawing was generated by the students; however, the documents lacked accurate information and detail. This prevented the author to build a precise structure, and it became difficult to uphold the original design intention. This resulted in an array of design improvisations and numerous questions similar to Request for Information (RFI) in the professional environment. Through this experience, the students learned the importance of a detailed construction document and communication between the design and construction team. Therefore, the team used multiple communication tools in addition to in-person meetings such as email, phone, live video conferencing, and group chat application for responding to RFIs. As shown in figures 4.1 and 4.2, the construction process has been shared via live video conferencing and received immediate design feedback from the students. The complications with the construction process provided very useful insight for their future career, and this handson learning experience had a profound impact on how they view the construction process.
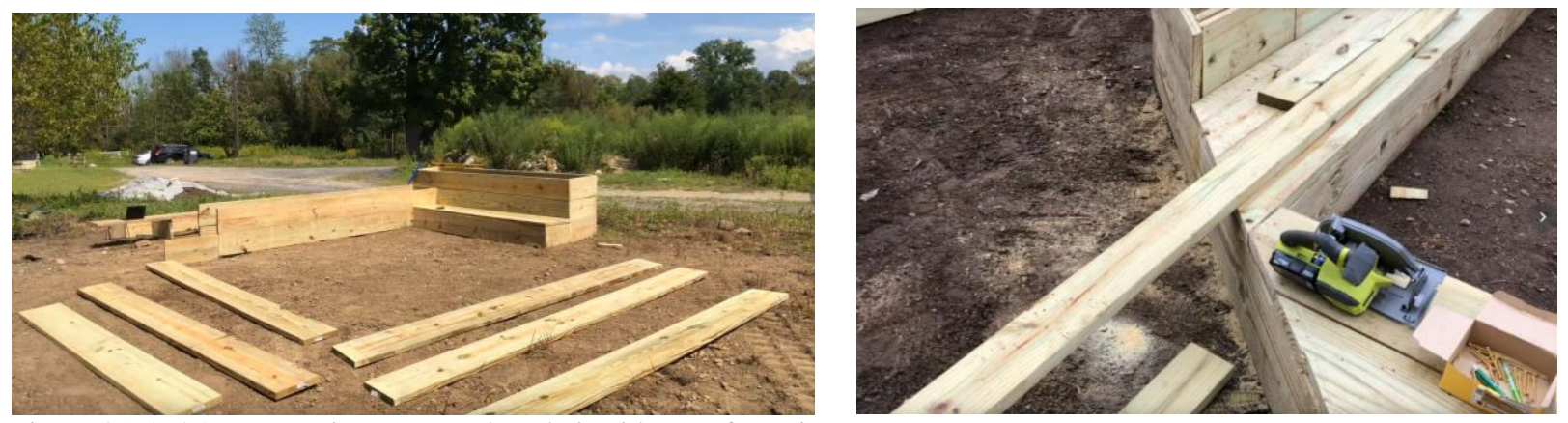

Figure $4.1 \& 4.2$ construction process shared via video conferencing

\section{Results}

The author interviewed with two participating students to ask about their learning experience. Also, to obtain a more in-depth understanding, the author required them to submit a report. The students responded that their representation and design skills improved during this study. While the improvement is not accurately quantifiable, one of the pieces of evidence is the faster drafting time. This efficiency allowed them to spend more time with their design. They also emphasized the importance of communication and understanding of the construction process. This experience not only provided technical knowledge, but it provided a broader perspective on the professional environment. Having this familiarity before full-time employment can give them more confidence in a new work environment. The participating student stated in her report, "The integration of furniture to raised beds and difference of heights makes this design exceptional. The anthropometric design and ergonomics are essential to assuring that the human body is comfortable by a reasonable position and capable of reaching crucial points in the raised 
beds and furniture. It also applies to safety at work, such as having a good posture while lifting materials. The garden project gave me a new perspective on construction. Before, I would understand the theory behind classes but still feel a gap of knowledge. Now, my mind is more open once the method learned last semester started to make sense in practice. It makes me more confident for future job interviews."

The overall cost was reported to Farmingdale State College, as shown below in table 3.1.

\begin{tabular}{|c|c|}
\hline Description & Amount \\
\hline 1. Lumber & $\$ 1,666.95$ \\
\hline 2. Circular Saw & $\$ 222.74$ \\
\hline 3. Deck Screws & 32.55 \\
\hline 4. Plants & $\$ \quad 216.15$ \\
\hline 5. Irrigation Timer & 42.66 \\
\hline 6. Irrigation System & 23.59 \\
\hline 7. Irrigation Hose & 33.87 \\
\hline Total & $\$ 2,238.61$ \\
\hline
\end{tabular}

Table 3.1 Material list and cost

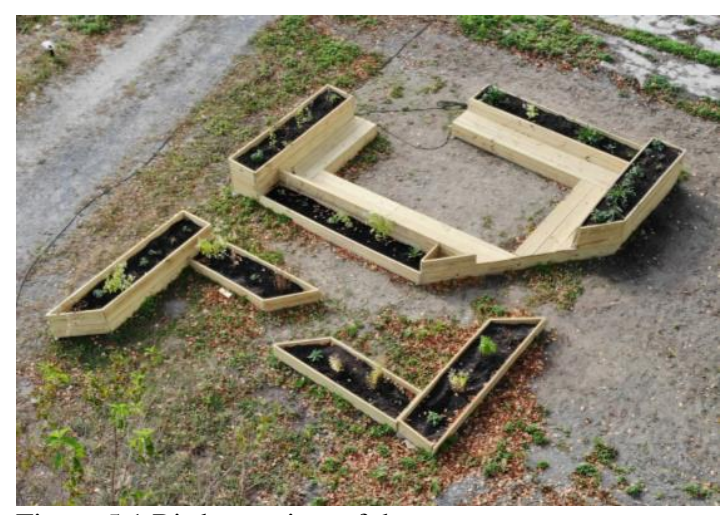

Figure 5.1 Birdseye view of the structure

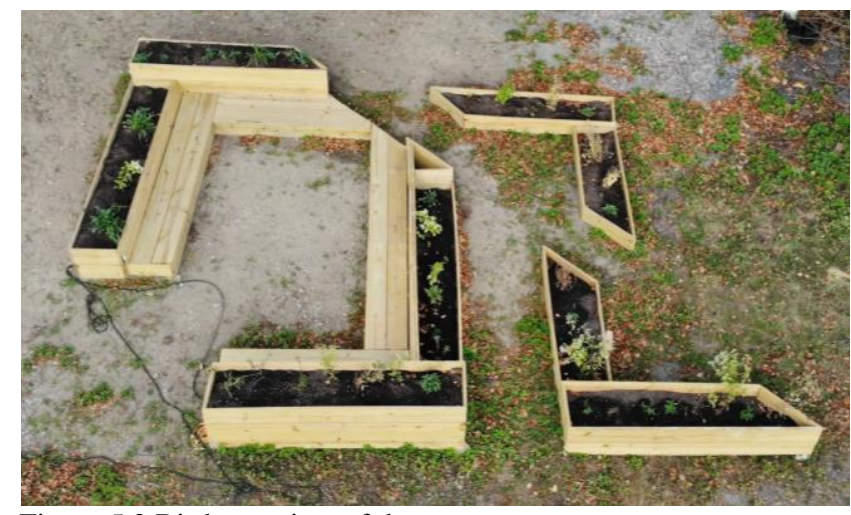

Figure 5.2 Birdseye view of the structure

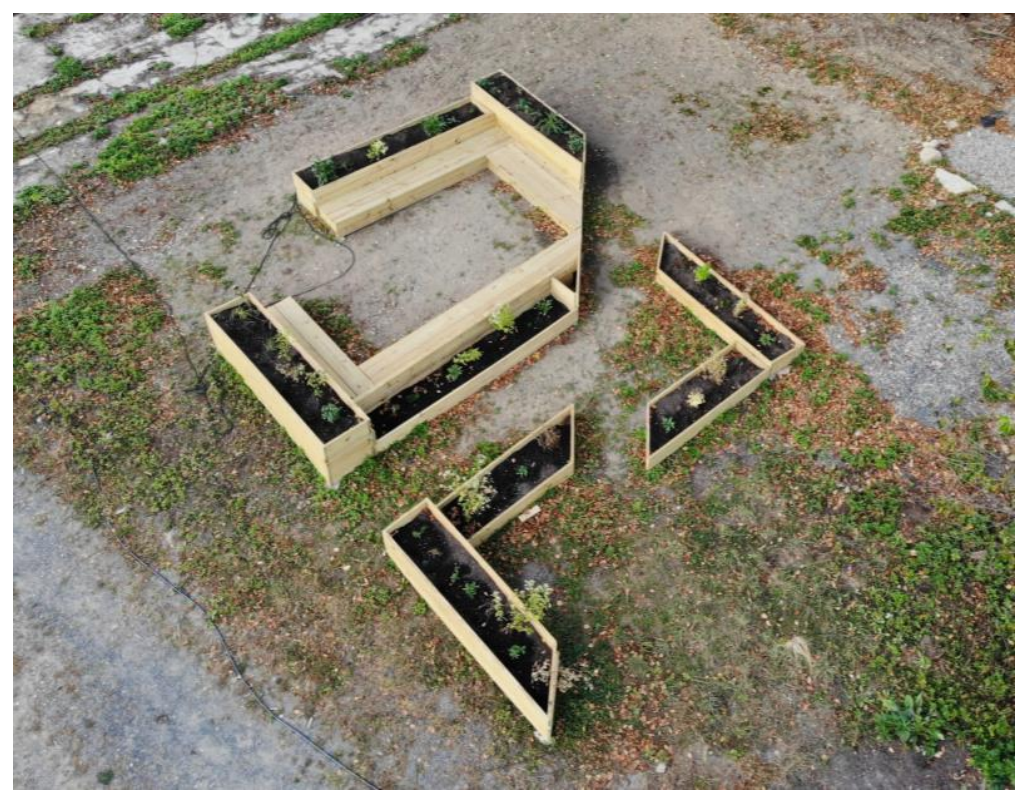

Figure 5.3 Birdseye view of the structure 


\section{Course implementation opportunity}

\section{Background}

This project is planned to be implemented in the Architectural Design I course in the spring term, 2021. This course has been offered to Architectural Engineering Technology students as a first course in the design course sequence from Architectural Design I through V. The course focuses on the fundamental principles of architectural form, space, and order. The students learn to develop design concepts, methods, processes, and ideation through the use of diverse learning activities such as lectures, discussions, research, sketching, modeling, presentations, and analysis. The course is comprised of (5) five design projects which begin with 3 weekly projects that cover the concept of form, space, and enclosure with physical model exercises. This weekly project focuses on the importance of fundamental knowledge that all the students need to retain in the beginning of this curriculum. The 4th project is a 3-week site design exercise that covers the topic of circulation. The 5 th project focuses on the ordering principles that use the residential building as the project scope. The last 5 weeks of the semester will be dedicated to the proposed project, which will cover the precedent study, site analysis, design, and construction of an outdoor garden structure.

\section{Coordination}

This multi-disciplinary project is being coordinated with the Department of Urban Horticulture $\&$ Design, which manages the Teaching and Sustainable garden on campus. The garden is used as a teaching facility to demonstrate practical horticultural and design skills, as shown in figure 7.1. According to the faculty member, there is an imminent need for the garden structure and design input for the garden layout. This site also is solely managed by the department, and it does not require an approval process from the facilities and management. This project aligns with the Architectural Design I course learning outcomes, which state that "the students are able to apply creativity in the design of systems, components or processes appropriate to program objectives". Also, the task overlaps with the course topics such as the concept of space, volume, form, enclosure, circulation, proportion, scale, and ordering principles. There is an inventory of lumber in the garden, but for any additional material, the budget may adjust from allocations from the Department of Urban Horticulture and on-campus grants.

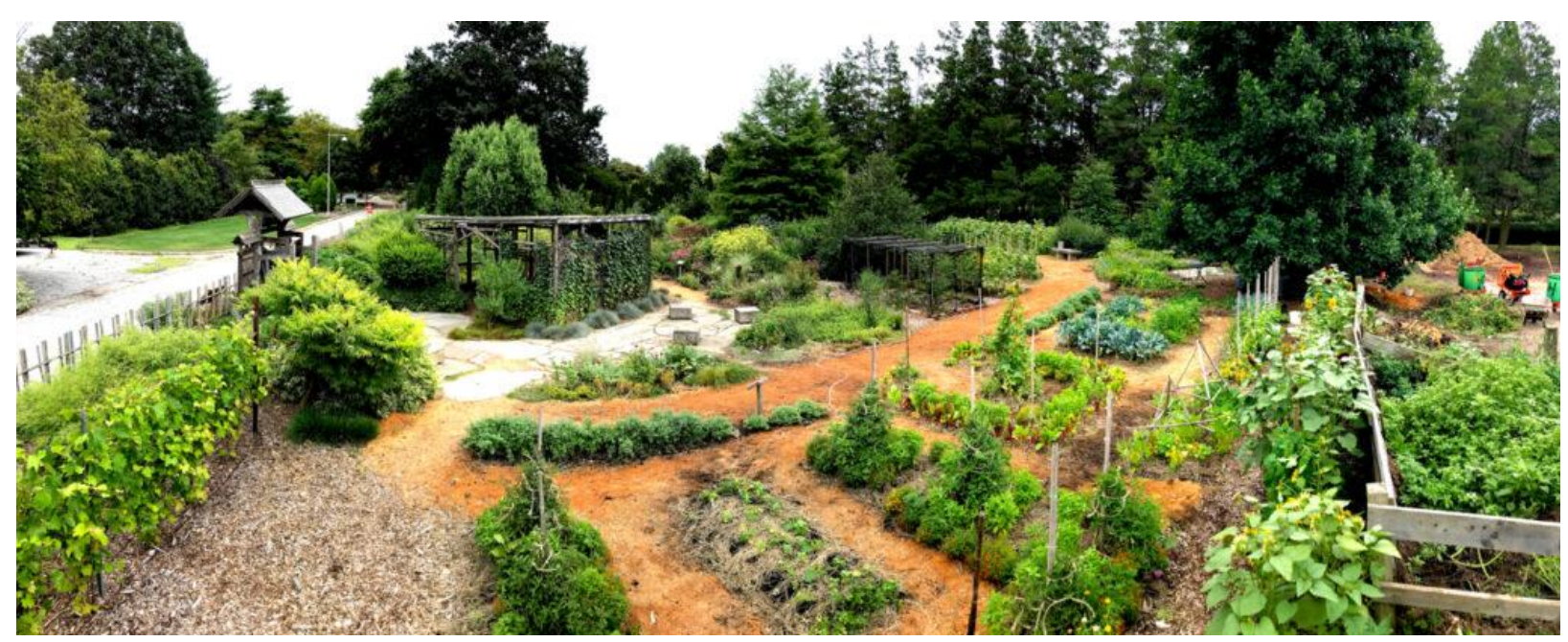

Figure 6.1 Teaching and sustainable garden 


\section{Group formation}

The student population will coincide with the number of students in the target course. Each section of the ARC 255 Architectural Design I course has between 16 to 18 students. The optimal structure for the project is to form a group of 3 people to develop a design, and the class will make a selection on the final design based on the presentation. Every group will take part in the construction process from sourcing the material, fabricating, preparing the site, and assembling based on the chosen design. This group structure promotes collaboration and cooperation with the team [8]. This is similar to professional collaboration in the architectural industry that projects rely on the expertise of diverse disciplines.

\section{Reflection}

This project aims to demonstrate the importance of a hands-on learning experience. Regretfully, the author did not have sufficient experience and foresight to avoid many of the challenges, such as budgeting, site access, estimating the timeline, IRB review process, and setting a better team structure during the construction phase. This research paper can provide insight to a wide audience in the academic community. The challenges and success of the full-scale construction project were equally revealing. Also, with the implementation of the future classroom setting, the author can provide more in-depth reporting of the search findings.

\section{References}

[1] E. Kwak, "Developing a Framework for a New Technical Elective: Prototyping Multifunctional Urban Micro-farms as an Experiential Learning Strategy for Architecture," in ASEE 2019 Annual Conference, Tampa, 2019.

[2] M. P. a. R. Felder, "Inductive Teaching and Learning Methods: Definitions, Comparisons, and Research Bases," Journal of Engineering Education, vol. 95, no. 04, pp. 123-137, 2006.

[3] B. Bloom, Taxonomy of Educational Objectives: The Classification of Educational Goals, New York: David McKay Company, 1956.

[4] B. Duch, S. E. Groh and D. E. Allen, The Power of Problem-Based Learning, Sterling, Virginia: Stylus, 2001.

[5] S. o. C. Environment, "Parsons Street Seat," Design Build, Parsons School of Design, 2019. [Online]. Available: https://www.parsonsstreetseats.com/.

[6] T. H. Line, "The High Line," The High Line, [Online]. Available: https://www.thehighline.org/.

[7] C. O’Neal and T. Pinder-Grover, "How can you incorporate active learning into your classroom?," Center for Research on Learning and Teaching, University of Michigan, [Online]. Available: http://crlt.umich.edu/sites/default/files/resource_files/Active\%20Learning\%20Continuum.pdf.

[8] B. J. Millis and P. G. Cottell, Cooperative Learning for Higher Education Faculty, Pheonix, AZ: Oryx Press, 1997. 